\title{
The yellow brick road: A values based curriculum model
}

\author{
Christopher McLean* \\ Faculty of Health Sciences, Building 67, Highfield Road, University of Southampton, Southampton SO17 1BJ, United Kingdom
}

\section{A R T I C L E I N F O}

\section{Article history:}

Accepted 2 November 2011

\section{Keywords:}

Care

Education

Ethics

Good character

Values based practice

\begin{abstract}
A B S T R A C T
Within the United Kingdom, the Nursing and Midwifery Council (NMC) requires that Nurses and Midwives are of 'good character' at the point of registration. This paper sets out how good character has been conceptualised within one UK Higher Education Institution and presents a model of "Values Based Enquiry" which aims to develop the "character' of students.

The paper presents three qualities ("the heart", "the nerve" and "the brain") which represent "good character' and which are believed to underpin values based Nursing or Midwifery practice. The development of these qualities is argued to be reliant upon helping students to develop intrinsic professional values of care and compassion.

The role of these character qualities in nursing practice and education is outlined, as are the ways in which they have led to the development of a model for Values Based Enquiry. This model represents a vision of the nature of professional education which may be shared by staff and students, whilst offering a model for learning and teaching based upon recognised educational principles. An argument is advanced that the adoption of a Values Based Enquiry model may develop and nurture the habits of mind which are necessary for the development of 'good character'.
\end{abstract}

(c) 2011 Elsevier Ltd. All rights reserved.

\section{Introduction}

Within the United Kingdom (UK), nurse education is regulated by the Nursing and Midwifery Council (NMC). In September 2010 the NMC produced new standards for nurse education (NMC, 2010a) which provide a stimulus to review all aspects of nursing curricula. Nursing and midwifery graduates in the UK are expected to be of 'good character' on entering the register (NMC, 2010a,b), and regardless of national context a concern for character development is a legitimate goal within nursing and midwifery education. This paper discusses the development of a "Values Based Enquiry" model for learning and teaching which seeks to develop 'good character', and which underpins one of the first curricula to be validated by the NMC under the new UK standards.

This paper outlines the ways in which 'good character' has been conceptualised and made central to the curriculum at one UK Higher Education Institution. The Values Based Enquiry (VBE) model will underpin all learning and teaching within these programmes, and was particularly commended by the NMC at the recent validation of these curricula.

Key principles of VBE are that 'good character' incorporates a commitment to, as well as a compliance with, normative codes of professional conduct (NMC, 2008, 2010a). The education of

\footnotetext{
* Tel.: +44 02380 598285; fax: +44 02380598909.

E-mail address: c.d.mclean@soton.ac.uk.
}

healthcare practitioners must therefore extend beyond teaching about care and compassion, but should aim to instill these core values.

\section{Development of the 'Yellow Brick Road' curriculum}

The VBE model presented in this paper has a theoretical foundation in the perspectives of Virtue Ethics and Values Based practice introduced below. However, the essence of the Values Based Enquiry model may be introduced by drawing upon the popular film "The Wizard of Oz" as a metaphor. Within the film Dorothy finds herself transported to the land of $\mathrm{Oz}$ and undertakes a journey along the Yellow Brick Road in order to get home. This journey may be seen as her struggle to determine where she herself is grounded as she tries to get home. Along the way she meets three companions (the Tin Man, the Cowardly Lion, and the Scarecrow) who may be seen to represent Dorothy's fears that she does not have "The Heart", "The Nerve" or "The Brain" to be who she wishes to be. By the end of the film we learn that there is no Wizard who can help Dorothy get home, whilst Dorothy learns that she did have these personal qualities all along.

This metaphor serves to highlight that nurse education is a journey of self-discovery, and that "The Heart", "The Nerve" and "The Brain" are qualities which are integral to the 'good character' of the nurse or midwife. Just as Dorothy ultimately realises that she had these qualities all along, educators cannot endow students 
with these qualities, but have a role in nurturing and inspiring students on their own personal journey. Ultimately, the curriculum may be characterised as a "Yellow Brick Road" which students follow in order to become the nurse or midwife which they themselves aspire to be.

\section{The heart, nerve and brain}

The sections below outline how the "Heart", "Nerve" and "Brain" have been conceptualised as central to both nursing practice and student learning.

\section{The heart}

Care and compassion are central to nursing and midwifery (NMC, 2010a; Hall and Ritchie, 2009; Chambers and Ryder, 2009). Respecting and valuing people as individuals is the foundation from which practitioners may avoid becoming trapped by limited conceptions of 'treatment' (Barker, 2009) and avoid what Benner (2000) describes as an 'objectifying gaze' in their interaction with others. A caring response may be considered as one which is contextual and grounded in a relationship in which others and self are valued (Gilligan, 1982; Tschudin, 2002). Care and compassion may thus be viewed as the disposition of the nurse or midwife to value and respond to others in ways which appreciate the human experience of healthcare.

This caring response may be facilitated by ensuring that practitioners have the skills to enter into caring relationships, and to ground their decision making in the personal values of the individuals for whom they care as well as 'facts' (Sullivan, 2009; Fulford, 2004). Gaining confidence in recognising and responding to the values of others requires skills of deep critical reflection, selfawareness in relation to personal behaviour and values, and a commitment to the professional values of care and compassion.

The Values Based Enquiry model aims to support students to maintain and develop these caring personal qualities and professional values. Students may be guided to develop their own intrinsic standards for excellence, and to set personal goals for the kind of nurse or midwife they wish to become (Spurr et al., 2010). Through these approaches, the values of care and compassion provide students' intrinsic motivation for study and generate a "teaching/learning climate" which fosters and supports the motivation which students require for effective learning (Biggs, 2002). The model further highlights that the commitment to act in accordance with these (freely chosen) professional values is ultimately a matter of personal integrity.

\section{The nerve}

Courage is frequently identified as central to the practice of nursing (Day, 2007; Lindh et al., 2010). Nurses and midwives must have the willingness and ability to advocate for others (NMC, 2008), and courage is an essential pre-requisite for "ethical, creative action" (Lindh et al., 2010). Forms of courage are also required for the assertive communication skills which are necessary in order to overcome barriers to patient safety (National Patient Safety Agency, 2007; NMC, 2010a).

Courage may be considered as being underpinned by core intrapersonal qualities of self-belief and personal efficacy. Within a practice context these qualities may be recognised as "moral agency" which Benner et al. (1999) describe as the practitioner's own sense of their ability to act upon or influence a situation. Practitioners are required to have the character and courage to speak out to 'make a difference' (Day, 2007). Self-efficacy has also been recognised as an essential pre-requisite for learning as people are more effective in all spheres when they have a 'learned optimism' in their approach to life (Knight and Yorke, 2003).
The VBE model therefore prompts students to reflect upon and challenge negative self-beliefs, and to consider ways in which they can achieve and make a difference in both theory and practice settings. Students can be supported in developing the belief that they can learn as a pre-requisite for 'learning to learn' and accepting responsibility for their own learning.

\section{The brain}

The transition to an all-graduate curriculum (NMC, 2010a) highlights that nurses and midwives are required to have well developed skills of critical analysis and an understanding of the science underpinning healthcare. These attributes are not gained solely in relation to theoretical learning, but are also developed within a practice context where experiential learning will promote the acquisition of knowledge and skills in a contextual and integrated manner (Savin-Baden, 2000).

As students gain skills and self-belief as independent learners, the VBE model highlights how they may develop the skills to critically analyse their practice, to ask questions of practice, to find and apply evidence to practice, and to generate evidence for and from practice. By integrating these skills within the context of wider personal and professional development, the learning journey is one which may be characterised as a "scholarly adventure" (Hinshaw, 1989).

\section{Developing the Values Based Enquiry model}

The Chief Nursing Officer for England has emphasised that education must be based upon explicit professional values (NMC, 2010a), whilst recent reports within the UK have raised concerns about whether the values of care and compassion are uniformly expressed in practice (Parliamentary and Health Service Ombudsman, 2011). The VBE model aims to ensure that the education of nurses and midwives extends beyond teaching about the values of care, compassion and respect for others, but explicitly seeks to instil these values.

The development of the VBE model was the vision of a whole curriculum development team, although these views were formalised, developed and articulated through achieving a synthesis between the two perspectives of Virtue Ethics and Values Based practice.

\section{Virtue ethics}

Virtue ethics are grounded in the work of Aristotle (1984) and such approaches are now widespread in healthcare (Pellegrino and Thomasma, 1993; Scott, 2000; Melia, 2004; Sellman, 2009). Two aspects of virtue theory are particularly significant in relation to the VBE model. Firstly, Aristotle (1984) suggests that virtues are dispositions which may be developed by habit ('ethics' has its roots in the Greek "ethos" meaning habit). Secondly, character may be conceptualised as the embodiment of those virtues or dispositions (especially the virtue of phronesis or practical wisdom) which serve to achieve a particular goal or aim (telos). In relation to the elements of the VBE model it may be noted that although caring is not itself an Aristotelian virtue, "having a virtue involves caring about the right things in the right way" (Allmark, 1998, p.467), and that courage (or 'nerve') is a cardinal virtue identified by Aristotle (1984).

Within the nursing literature, writers such as Gastmans (2002), Armstrong (2006), and Sellman (2009) adopt virtue ethics approaches based on a particular concept of 'practice'. Macintyre (1985) conceptualises a 'practice' as (broadly) a coherent and complex form of human activity which has its own goals, its own standards of excellence, and its own virtues. Authors considering 
nursing as a practice in this sense have begun to outline the virtues which may be considered specific to nursing practice such as openmindedness (Sellman, 2003). This paper presents 'characteristics' of graduate nurses and midwives which may be considered as embodying virtues which are indicative of 'good character'. The VBE model presented here is intended to reinforce the habits of mind which lead to their development.

\section{Values based practice}

Values-based practice is an approach with roots in mental health practice which recognises that our own personal values, and the values or service users are inescapable and inextricably linked in every aspect of clinical practice and decision making (Fulford, 2004).

The need for Values-Based approach is made clear by the recognition that the values of service users can easily be overlooked in clinical decision making, and that patient-centred decision making requires a responsiveness to the values of others (Seedhouse, 2006). In part, this can be attributed to our tendency to presume that values are shared except where there is clear evidence that values are conflicting (Fulford, 2004).

Values-Based approaches therefore recognise that healthcare professionals need to develop skills which enable them to develop a knowledge and awareness of values, and the abilities to reason and work with values (Woodbridge and Fulford, 2004). Valuesbased practice therefore requires self-awareness (so as to remain aware of our own values and the ways they direct our behaviour), and the skills necessary to recognise and respond to the values of others.

\section{The Values Based Enquiry model}

All the above influences come together in a model for Values Based Enquiry which emphasises that self-awareness, the professional values of care and compassion, and an awareness of the values of others are central to the students developing identity as a nurse or midwife. The centre of the model (presented in Fig. 1) relates to these three elements, and together require the student to consider their own identity as a developing practitioner.

Fig. 1 highlights that students are at all times required to be aware of their own values and behaviour; to be mindful of the professional values of care and compassion they wish to embody; and consider how they are relating and responding to others. Together, these elements come together to challenge the student to consider the question of whether they are now behaving like the practitioner they wish to become. It is through maintaining this focus on developing professional identity that the curriculum represents a 'Yellow Brick Road' or journey of self-discovery.

It is recognised that students need support in sustaining and developing their "moral identity" throughout their studies (Randle, 2002), and placing a focus on becoming the nurse or midwife they wish to become challenges students to see ethical practice as something they 'are' rather than simply something that they 'learn'

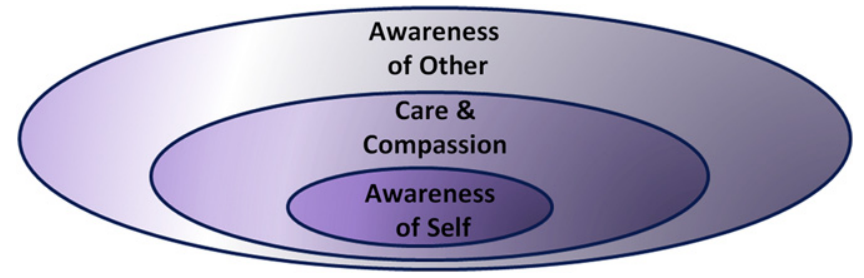

Fig. 1. to do (Holt, 2006). In this way the VBE model acknowledges that ethics is the heart of healthcare (Seedhouse, 2009), and accepts the curriculum as a form of "moral education" (Sellman, 2009).

Sellman (2009) has further suggested that "professional wisdom" requires the practitioner to know what they know or do not know, to be able to learn that which they do not yet know, and to be willing to act in order to address short-comings in their knowledge and competence. With this in mind, three sets of prompt questions have been developed around the core of the model which may guide further learning and development. This results in the full VBE model presented within Fig. 2.

These prompt questions foster a recognition that the professional values of care and compassion ('the Heart'); may provide motivation for learning. Students also need to consider and overcome barriers to personal efficacy which may inhibit their learning or practice (develop 'the Nerve'), and develop the skills to generate or find evidence which supports or questions their practice (develop 'the Brain'). These prompt questions therefore aim to foster the habits of mind necessary to develop the 'Heart', 'Nerve' and 'Brain' required for practice.

The VBE model is designed to be used as the basis for learning within regular seminar groups as students reflect upon practice experiences, or explore scenarios in the context of theoretical learning. However, the model also represents a philosophy which is shared by students and staff, and the ways in which it may guide learning can be illustrated with reference to the following examples.

Example 1: A student whose attendance at lectures is sporadic and who states when challenged that lectures are 'boring'

Asking the student to reflect on whether they are behaving like the practitioner they wish to become could be a powerful challenge. This may prompt reflection on their own values and commitment to their course of study (self-awareness), and upon the knowledge and skills which they may need to develop in order to meet the needs of others (awareness of others' values). This may challenge such a student to reconsider their views on the nature of professional caring and re-evaluate their own commitment to the course.

A consideration of the question "what are the barriers to my learning" may lead to the student raising legitimate concerns regarding the quality of teaching, or to a consideration of the study skills which the student needs to develop. Reflecting on self-belief may also lead the student to consider whether they have any underlying beliefs regarding their inability to cope with academic challenges.

Example 2: A student who reports concern at the moving and handling practices which they have felt obliged to participate in during a recent practice experience.

Reflection on the students own values and commitment to providing high quality care may lead to a recognition that they have not been practising to a standard which they would wish and prompt a recognition that they need to reconsider the knowledge and skills they need to develop.

In this instance it is likely that the student has experienced barriers to their "being the practitioner they want to be". Exploration of these issues may lead the student to reflect upon the ways in which they are influenced by others or by the prevailing culture of a health care setting and to consider future ways of responding assertively and with integrity.

Perceived disparities between what is experienced in clinical areas and 'taught' theory may lead students to uncover and identify questions for their practice and to begin deeper exploration of the evidence for and from practice 


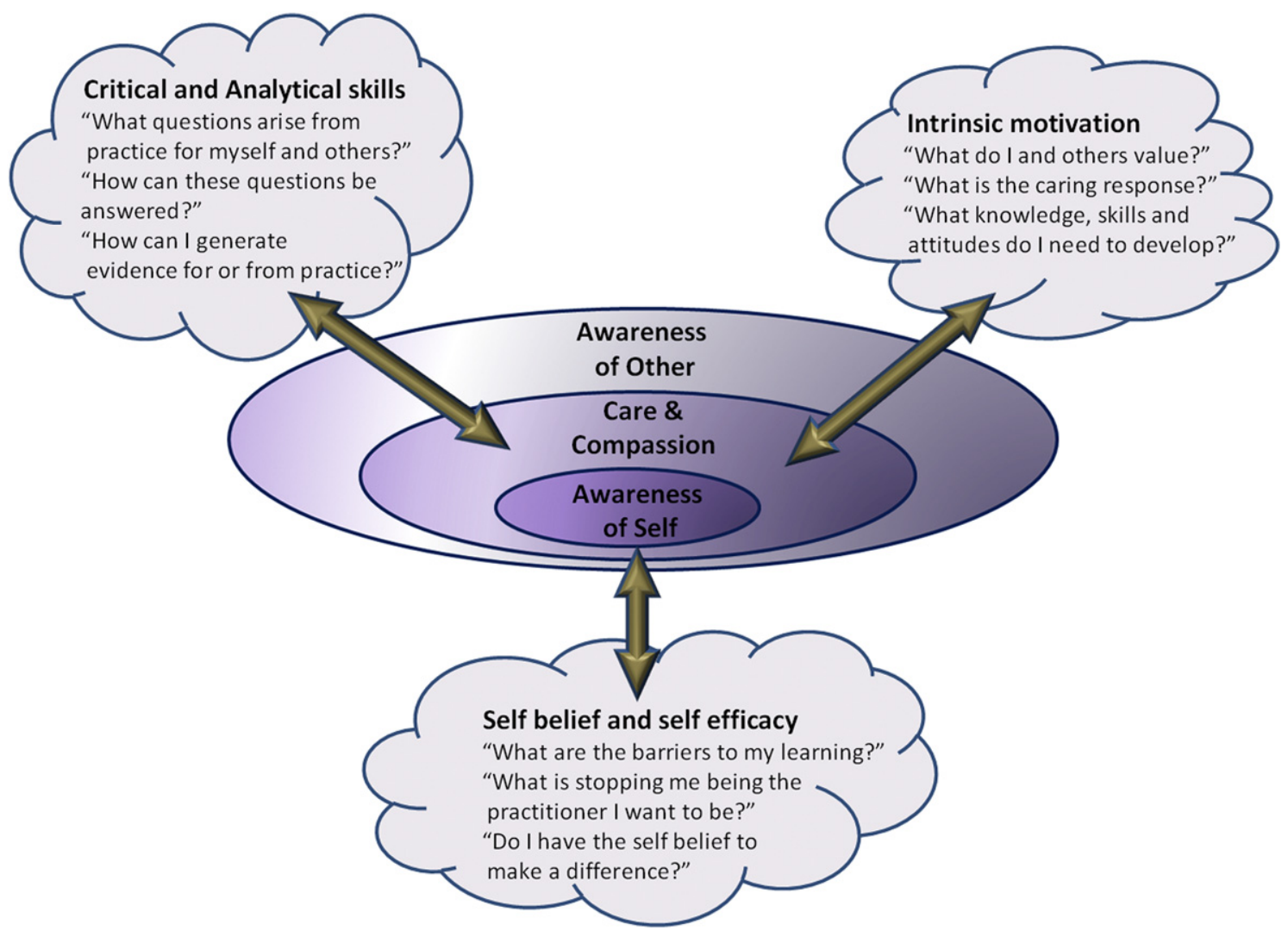

Fig. 2. The Values Based Enquiry model.

Example 3: A student who questions whether they have an obligation to provide bystander cardio-pulmonary resuscitation (CPR) Self-awareness demands that the student initially reflect upon the motivations behind the question. Consideration of the needs and values of others, together with the question "what is the caring response?" lead powerfully to the conclusion that this is to provide CPR.

These initial considerations may then lead to an exploration of the additional knowledge and skills which students may need to develop. Additional learning regarding a range of practice skills, legal and professional issues will enable students to make judgments such that they are equipped to provide a caring response whilst managing any potential risks to themselves or others in such circumstances.

These examples represent questions which may be faced early in students' programmes where the use of the model may primarily be led by academic staff. Regular use of the model aims to support students in developing 'habits of mind' such that later in their programme Values Based Enquiry groups will primarily take the form of clinical supervision sessions run independently by and for students.

The above examples illustrate that use of the VBE model requires making judgements regarding which 'prompt questions' are the most pertinent to a given situation. In making these judgements academic staff role model the 'professionally wise' practitioner (Sellman, 2009; Perry, 2009) whilst seeking to inspire students through communicating the need for intrinsically held professional values. The above example relating to CPR particularly highlights that such a challenge is not an expression of a personal morality, but that the development of moral character is central to nurse and midwifery education and that staff have a responsibility to provide inspirational role models.
Within Values Based Enquiry, elements of reflection, ethical responsiveness, learning to learn and higher order academic skills are seen as synergistically entwined rather than as separate activities or 'stages'. Although the VBE model therefore does not clearly correlate with previously described cyclical models of reflection or learning (e.g. Kolb, 1984; Gibbs, 1988) it may nonetheless be used as such a process model. The VBE model may generate questions for exploration, but is not prescriptive in relation to the ways in which learning may be facilitated. Educationalists who are familiar with strategies such as problem based learning (Schmidt, 1983) or enquiry based learning (Grandis et al., 2003) will be able to use these approaches in order to guide learning across the curriculum.

\section{Conclusion}

The Values Based Enquiry model has been designed to underpin an all-graduate curriculum under the new NMC (2010) standards for nurse education within the UK. Although developed within this context, the VBE model reflects an explicit conceptualization of the nature of professional education which may be of wider relevance.

The VBE model represents a vision of the nature of professional preparation which may be understood and shared by staff and students. It recognises that the professional values of care and compassion are not only central to nursing and midwifery practice, but may also provide the intrinsic motivation for students to learn. VBE may aid students in "learning to learn" and in developing critical and analytical skills such that they are able to develop the knowledge and skills which they will require to deliver care in the future. Finally the model aims to ensure that students develop the self-efficacy and moral agency necessary to make a difference for individuals through the delivery of values based, person-centred care, and to influence and lead others in the delivery of development of future services. 
This paper has shared the ways in which one educational institution has conceptualized a view that nursing and midwifery education and practice must be based upon values. The Values Based Enquiry model demonstrates that values may be used to underpin a model for education such that the education of nurses and midwives may explicitly aim to develop 'good character'.

\section{Acknowledgement}

The author acknowledges the contribution of the whole University of Southampton curriculum development team, and that of Cathy Sullivan in particular, to the development of the ideas articulated in this paper.

\section{References}

Allmark, P., 1998. Is caring a virtue? Journal of Advanced Nursing 28 (3), 466-472. Aristotle, 1984. Nicomachean ethics. In: Barnes, J. (Ed.), The Complete Works of Aristotle, vol. 2. Princeton University Press, Princeton (Revised Oxford Translation).

Armstrong, A.E., 2006. Towards a strong virtue ethics for nursing practice. Nursing Philosophy 7 (3), 110-124.

Barker, P., 2009. Psychiatric and Mental Health Nursing: The Craft of Caring. Hodder Arnold, London.

Biggs, J., 2002. Teaching for Quality Learning at University. Open University Press, Buckingham.

Benner, P., Hooper-Kryiakidis, P., Stannard, D., 1999. Clinical Wisdom and Interventions in Critical Care. A Thinking in Action Approach. Saunders, Philadelphia.

Benner, P., 2000. The wisdom of our practice. American Journal of Nursing 100 (10) 99-105.

Chambers, C., Ryder, E., 2009. Compassion and Caring in Nursing. Radcliff Publishing, Oxford.

Day, L., 2007. Courage as a virtue necessary to good nursing practice. American Journal of Critical Care 16 (6), 613-616.

Fulford, K.W.M., 2004. Ten principles of values-based medicine. In: Radden, J. (Ed.) The Philosophy of Psychiatry: A Companion. Oxford University Press, New York, pp. 205-234.

Gastmans, C., 2002. A fundamental ethical approach to nursing: some proposals for ethics education. Nursing Ethics 9 (5), 494-507.

Gibbs, G., 1988. Learning By Doing: A Guide to Teaching and Learning Methods. Further Education Unit, Oxford Brookes University, Oxford.

Gilligan, C., 1982. In a Different Voice. Psychological Theory and Women's Development. Harvard University Press, Cambridge Massachusetts.

Grandis, S., Long, G., Glaspar, A., Jackson, P. (Eds.), 2003. Foundation Studies for Nursing, Using Enquiry-based Learning. Palgrave, Basingstoke.

Hall, C., Ritchie, D., 2009. What is Nursing? Exploring Theory and Practice. Learning Matters, Exeter.
Hinshaw, A., 1989. Nursing science: the challenge to develop knowledge. Nursing Science Quarterly 2 (4), 162-171.

Holt, J., 2006. Exploring Learning \& Teaching Ethics in the Nursing Curriculum (Health Sciences and Practice Mini Project). Higher Education Academy.

Kolb, D.A., 1984. Experiential Learning: Experience as the Source of Learning and Development. Prentice-Hall Inc., New Jersey.

Knight, P., Yorke, M., 2003. Learning, Curriculum and Employability. Routledge/ Falmer, London.

Lindh, I.-B., da Silva, A.B., Berg, A., Severinsson, E., 2010. Courage and nursing practice: a theoretical analysis. Nursing Ethics 17 (5), 551-565.

MacIntyre, A., 1985. After Virtue, second ed. Duckworth, London.

Melia, K., 2004. Health Care Ethics. Lessons from Intensive Care. Sage Publications, London.

National Patient Safety Agency (NPSA), 2007. Recognising and Responding Appropriately to Early Signs of Deterioration in Hospitalised Patients. NPSA, London.

Nursing and Midwifery Council (NMC), 2008. The Code: Standards of Conduct Performance and Ethics For Nurses and Midwives. NMC, London.

Nursing and Midwifery Council (NMC), 2010a. Standards for Pre-Registration Nursing Education. NMC, London.

Nursing and Midwifery Council (NMC), 2010b. Good Health and Good Character: Guidance For Approved Higher Education Institutions (Revised). NMC, London.

Parliamentary and Health Service Ombudsman, 2011. Care and Compassion? Report of the Health Service Ombudsman on Ten Investigations into NHS Care of Older People. HMSO.

Pellegrino, T., Thomasma, D., 1993. The Virtues in Medical Practice. Oxford University Press, Oxford.

Perry, B., 2009. Role modeling excellence in clinical nursing practice. Nurse Education in Practice 9 (1), 36-44.

Randle, J., 2002. The shaping of moral identity and practice. Nurse Education in Practice 2 (4), 251-256.

Savin-Baden, M., 2000. Problem-based Learning in Higher Education: Untold Stories. Oxford University Press, Oxford.

Schmidt, H.G., 1983. Problem-based learning: rationale and description. Medical Education 17 (1), 11-16.

Scott, P.A., 2000. Emotion, moral perception, and nursing practice. Nursing Philosophy 1 (2), 123-133.

Seedhouse, D., 2006. Values-based Decision-making For the Caring Professions. Wiley, Chichester.

Seedhouse, D., 2009. Ethics: The Heart of Health Care, third ed. Wiley, Oxford.

Sellman, D., 2003. Open-mindedness: a virtue for professional practice. Nursing Philosophy 4 (1), 17-24.

Sellman, D., 2009. Practical wisdom in health and social care: teaching for professional phronesis. Learning in Health and Social Care 8 (2), 84-91.

Spurr, A., Bally, J., Ferguson, L., 2010. A framework for clinical teaching: a passioncentered philosophy. Nurse Education in Practice 10 (6), 349-354.

Sullivan, C., 2009. Values based practice. In: Childs, L., Coles, L. (Eds.), Essential Skills Clusters for Nursing - Theory for Practice. Wiley, Oxford.

Tschudin, V., 2002. Ethics in Nursing. The Caring Relationship, third ed. Butterworth Heinemann, London.

Woodbridge, K., Fulford, K.W.M., 2004. 'Whose Values?' A Workbook For Valuesbased Practice in Mental Health Care. The Sainsbury Centre for Mental Health, London. 